\title{
Uptake of bleomycin by human brain tumours ${ }^{1}$
}

\author{
T. HAYAKAWA ${ }^{2}$, Y. USHIO, K. MORIMOTO, H. HASEGAWA, \\ H. MOGAMI, AND K. HORIBATA \\ From the Department of Neurosurgery, Osaka University Medical School, Osaka, \\ and Institute of Microbial Chemistry, Tokyo, Japan
}

SYNOPSIS The uptake of bleomycin (BLM) by various types of brain tumours after intravenous or intrathecal administration was investigated by bioassay in 67 patients. The correlation between the BLM distribution and the type and characteristics of brain tumours was studied.

Bleomycin (BLM), discovered by Umezawa et al. $(1966 \mathrm{a}, \mathrm{b})$ is a kind of cytostatic antibiotic complex produced by a strain of Streptomyces verticillus, and was found by Ichikawa et al. $(1967,1968)$ to be highly effective against human squamous cell carcinoma. These authors observed relatively high concentration of BLM in the skin after subcutaneous injection in mice, and suggested that the therapeutic effect on squamous cell carcinoma might be related to the high concentration of BLM in the skin (Ichikawa et al., 1967; Umezawa et al., 1967, 1968a, b).

Recently, Mamo et al. (1973) found that radioactive BLM $\left({ }^{57} \mathrm{Co}-\mathrm{BLM}\right)$ was superior to technetium-99m (Tc-99m) for the diagnosis of malignant intracranial tumours, and Takeuchi et al. $(1969,1972)$ reported clinical effects of BLM against brain tumours.

The purpose of the present study is to investigate the uptake of BLM by various types of brain tumours and to study the correlation between the distribution of BLM and the type and characteristics of brain tumours.

\section{METHODS}

The investigation was carried out in 67 patients with various types of intracranial tumours. The types of tumours and numbers of patients examined are listed in Table 1.

BLM was administered, $1 \mathrm{mg} / \mathrm{kg}$ of body weight

1 This work was supported in part by grants-in-aid for Fundamental Scientific Research from the Ministry of Public Welfare and from the Ministry of Education.

2 Address for reprint requests: Dr Toru Hayakawa, Department of Neurosurgery, Osaka University Hospital, 3-Dojima-hamadori, Fukushima-ku, Osaka, Japan.

(Accepted 11 November 1975.)
TABLE 1

TYPE OF TUMOUR AND NUMBERS OF PATIENTS

\begin{tabular}{lrr}
\hline Glioma & & 25 \\
$\quad$ Glioblastoma & 13 & \\
$\quad$ Astrocytoma (grade II) & 6 & \\
$\quad$ Ependymoma & 2 & \\
$\quad$ Oligodendroglioma & 1 & \\
$\quad$ Medulloblastoma & 3 & 16 \\
Meningeal tumours & & \\
$\quad$ Meningioma & 12 & \\
$\quad$ Malignant meningioma & 3 & 11 \\
$\quad$ Primary sarcoma & 1 & 4 \\
Craniopharyngioma & & 3 \\
Pituitary adenoma & & 1 \\
Schwannoma & & 1 \\
Microgliomatosis & & 4 \\
Haemangioblastoma & & 67 \\
Choriocarcinoma & & \\
Metastatic tumour & & \\
\hline Total & & \\
\hline
\end{tabular}

intravenously in 64 patients and $0.05 \mathrm{mg} / \mathrm{kg}$ intraventricularly through a ventricle drain in three patients, at a time prospectively two hours before the collection of intracranial tumour specimens by surgery. The collection of tumour specimens was performed as soon as possible after craniotomy. Five millilitres of blood were also collected from a subcutaneous vein for BLM measurement of plasma samples at the time just before BLM administration and at the time of tumour sample collection. The tissue sample, a part of which was used for histological examination, was homogenized by a Teflon homogenizer in physiological saline solution and centrifuged. The supernatant fluid was used for assay.

BLM concentration was determined by antibacterial bioassay in the paper disc method using B. subtilis. The minimum assayable concentration 


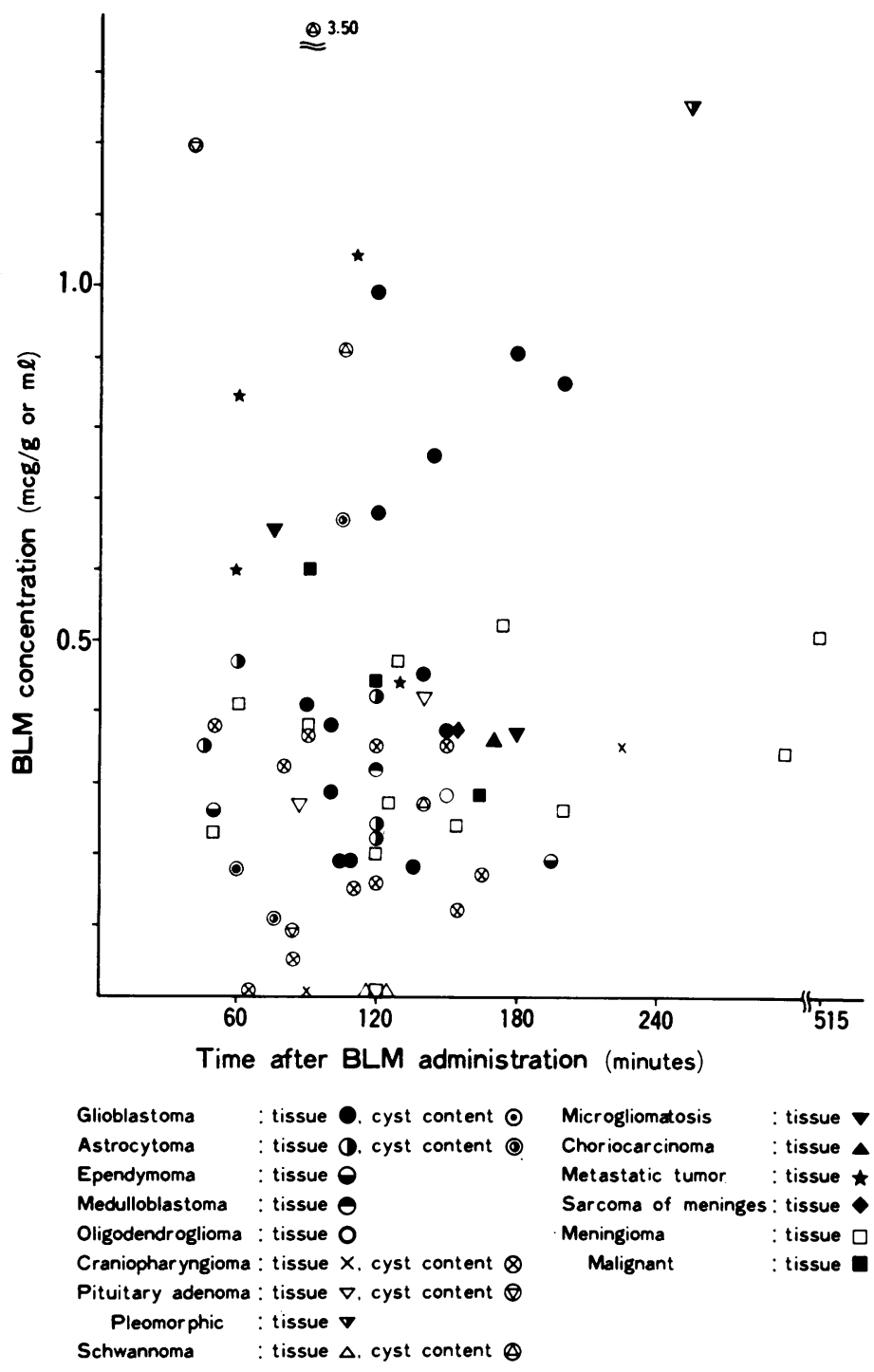

FIG. 1 BLM concentration in tumour tissue or cyst content of intracranial tumours after intravenous administration.

was $0.01 \mu \mathrm{g} / \mathrm{ml}$. The method has been described in detail by Hayakawa et al. (1974).

Antibacterial drugs were not used before and during the surgery until the specimens were collected. Cases in which the plasma sample collected before BLM administration showed antibacterial activity against $B$. subtilis spores were excluded from the present data.

Before surgery, the patients were examined by serial cerebral angiography with $60 \%$ Urografin and by brain scintillography with Tc-99m pertechnetate.

\section{RESULTS}

INTRAVENOUS ADMINISTRATION OF BLM Some concentrations of BLM were detected by bioassay in 49 specimens of tumour tissue out of 53 examined, and in 17 specimens of cyst contents out of 18.

The BLM concentrations of tumour varied considerably; the concentrations of tumour tissue ranged from 0 to $1.25 \mu \mathrm{g} / \mathrm{g}$ and the concentrations of cyst contents, from 0 to $3.50 \mu \mathrm{g} / \mathrm{ml}$. 
TABLE 2

BLM CONCENTRATION IN TUMOUR TISSUE AND CYST CONTENTS OF INTRACRANIAL TUMOURS AFTER INTRAVENOUS ADMINISTRATION (1 mg/kg, intravenously)

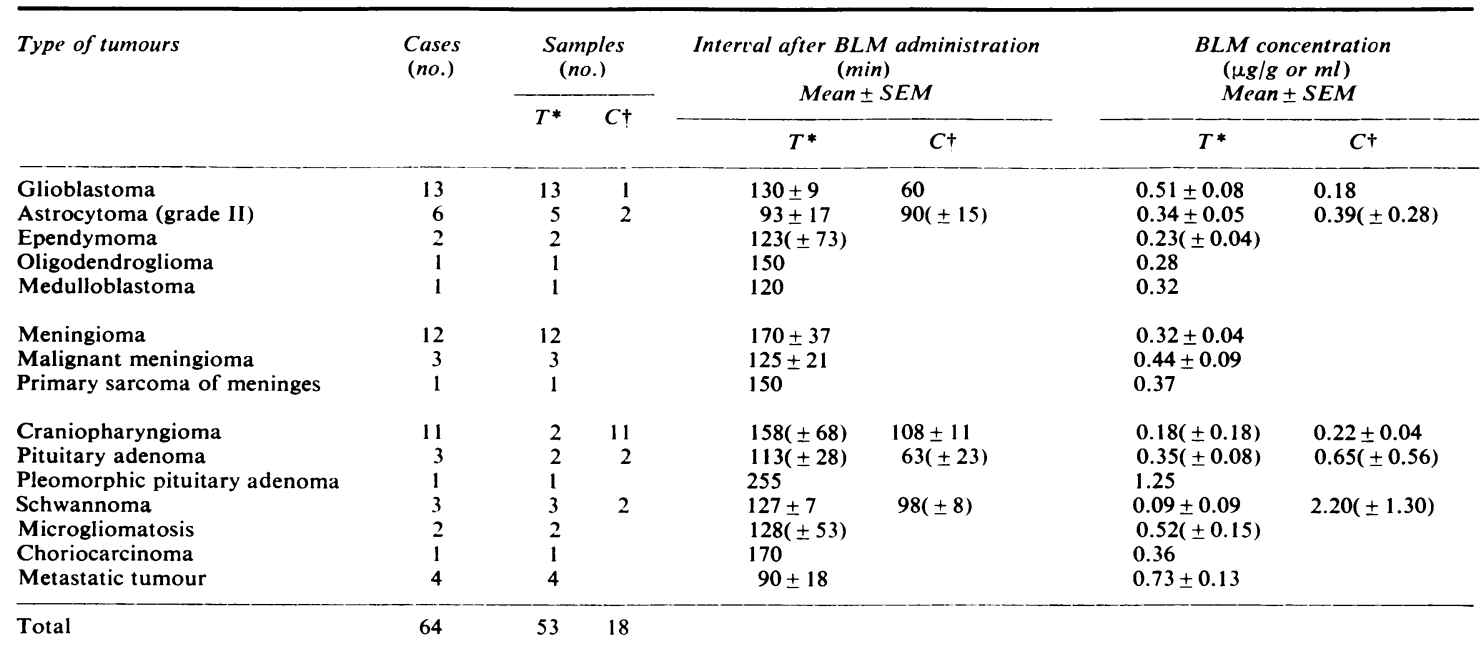

* Tumour tissue. $\quad+$ Cyst contents.

The numbers in parentheses refer to the range of intervals and concentrations obtained.

TABLE 3

COMPARISON OF TUMOUR WITH PLASMA CONCENTRATION RATIO OBTAINED DURING $120 \pm 30$ MINUTES AFTER INTRAVENOUS ADMINISTRATION OF BLM BASED ON FINDINGS OF HISTOLOGICAL EXAMINATION, ANGIOGRAPHY OF BRAIN, AND BRAIN SCAN WITH TC-99M OF TUMOURS

\begin{tabular}{|c|c|c|c|}
\hline $\begin{array}{l}\text { Examination and } \\
\text { findings }\end{array}$ & $\begin{array}{l}\text { Cases } \\
\text { (no.) }\end{array}$ & $\begin{array}{c}\text { Tumour/plasma } \\
\text { ratio } \\
\text { Mean } \pm \text { SEM }\end{array}$ & $\begin{array}{c}\text { Statistical } \\
\text { difference } \\
t\end{array}$ \\
\hline \multicolumn{4}{|l|}{ Histological } \\
\hline Malignant & 20 & $0.45 \pm 0.08$ & Significant \\
\hline Benign & 11 & $0.10 \pm 0.03$ & $(P<0.01)$ \\
\hline \multicolumn{4}{|l|}{ Angiography } \\
\hline Tumour stain + & 12 & $0.38 \pm 0.10$ & Not significant \\
\hline Tumour stain - & 19 & $0.30 \pm 0.08$ & $(P>0.05)$ \\
\hline \multicolumn{4}{|l|}{ Brain scan } \\
\hline Positive & 20 & $0.28 \pm 0.06$ & Not significant \\
\hline Negative & 3 & $0.26 \pm 0.07$ & $(P>0.05)$ \\
\hline
\end{tabular}

Each BLM concentration obtained has been plotted, with the difference of tumour types against the collected time after BLM administration in Fig. 1, and the mean concentrations and collected times in each type of tumours are summarized in Table 2.

High tissue concentrations were obtained in the metastatic tumours, glioblastomas, and microgliomatosis. Above all, the concentration of metastatic tumours was remarkably high with statistically significant difference from that of astrocytoma $(\mathrm{P}<0.02)$ and meningioma $(\mathrm{P}<$ 0.001).

It can be seen that there was a tendency for the more malignant tumours to have higher tissue concentrations among those tumours with histologically similar origins-for example, the concentration in glioblastoma compared with other gliomas, the concentration of malignant meningioma or pleomorphic type of pituitary adenoma compared with the ordinary benign form of the respective tumours.

As to the BLM concentrations of cyst contents, the markedly high concentrations were observed in both of two Schwannomas of the 8 th cranial nerve and one out of two pituitary adenomas, while the cyst content concentrations of craniopharyngioma were usually not so high.

The ratios of tumour tissue and cyst contents to plasma concentration $(\mathrm{T} / \mathrm{P}$ ratio and $\mathrm{C} / \mathrm{P}$ ratio) have been plotted, with difference of tumour types against the collected times in Fig. 2. The values of $\mathrm{T} / \mathrm{P}$ ratios ranged from 0 to 2.63 


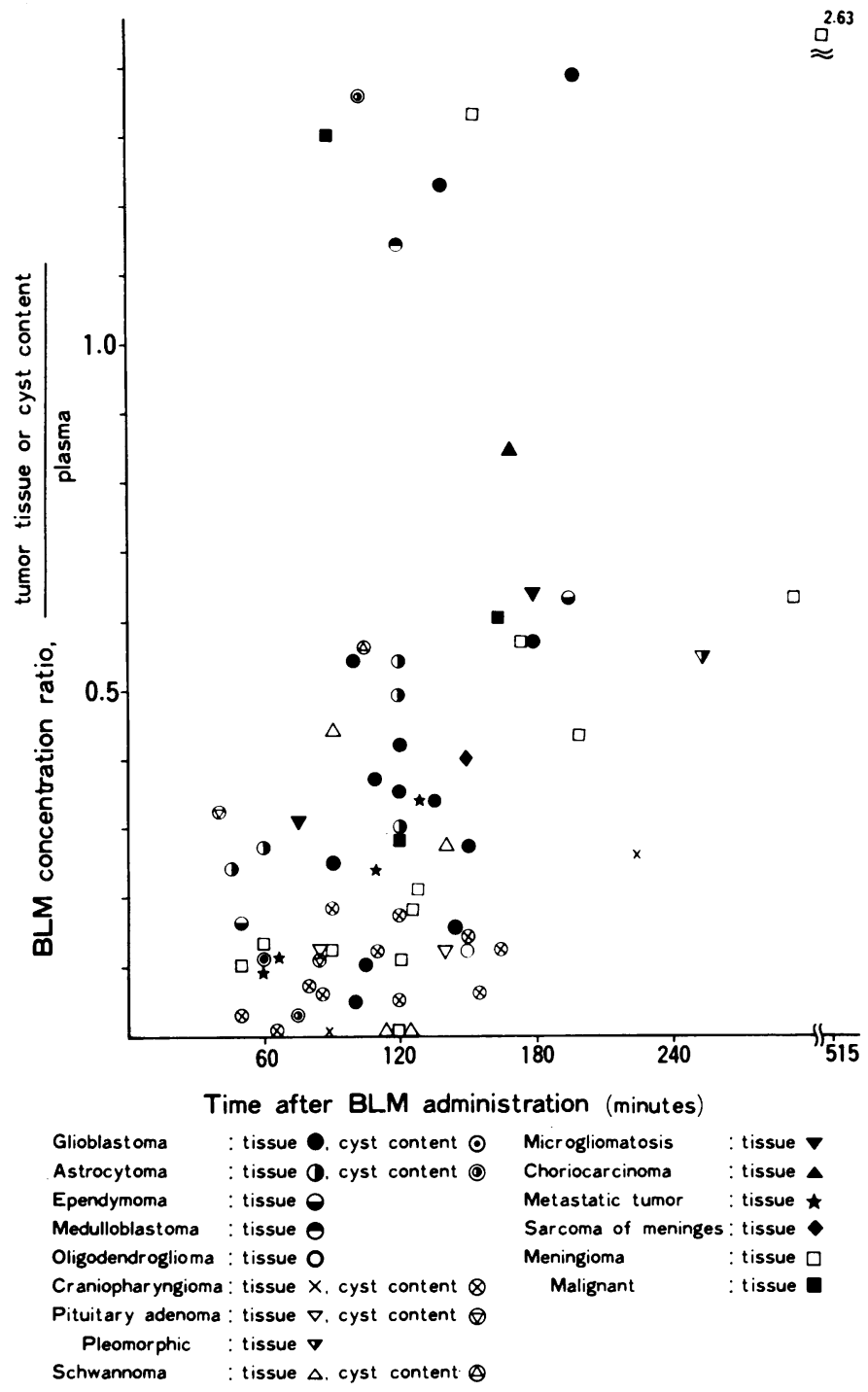

FIG. 2 Bleomycin (BLM) concentration ratio of tumour tissue or cyst content to plasma after intravenous administration.

and those of $\mathrm{C} / \mathrm{P}$ ratios, from 0 to 1.35 . There is an apparent tendency for $\mathrm{T} / \mathrm{P}$ or $\mathrm{C} / \mathrm{P}$ ratios of the samples collected later after BLM administration to be higher than those collected earlier.

Figures 3, 4, and 5 illustrate the correlation between the $T / P$ ratios and the histological malignancy, the tumour stain on cerebral angiograms, and the findings on brain scintillography with Tc-99m. Statistical comparisons were done with the data of the samples collected during the restricted period at $120 \pm 30 \mathrm{~min}$ after BLM administration as listed in Table 3. There is evidence of a high statistical correlation between the BLM uptake by a tumour and the malignancy of that tumour, though there may not be significant correlation between the BLM distribution in the tumour and the presence of tumour stain on cerebral angiograms or the positive findings of brain scintillography with Tc-99m.

The specimens of brain tissue in the vicinity of the tumour were unintentionally collected for BLM measurement at the time of tumour re- 


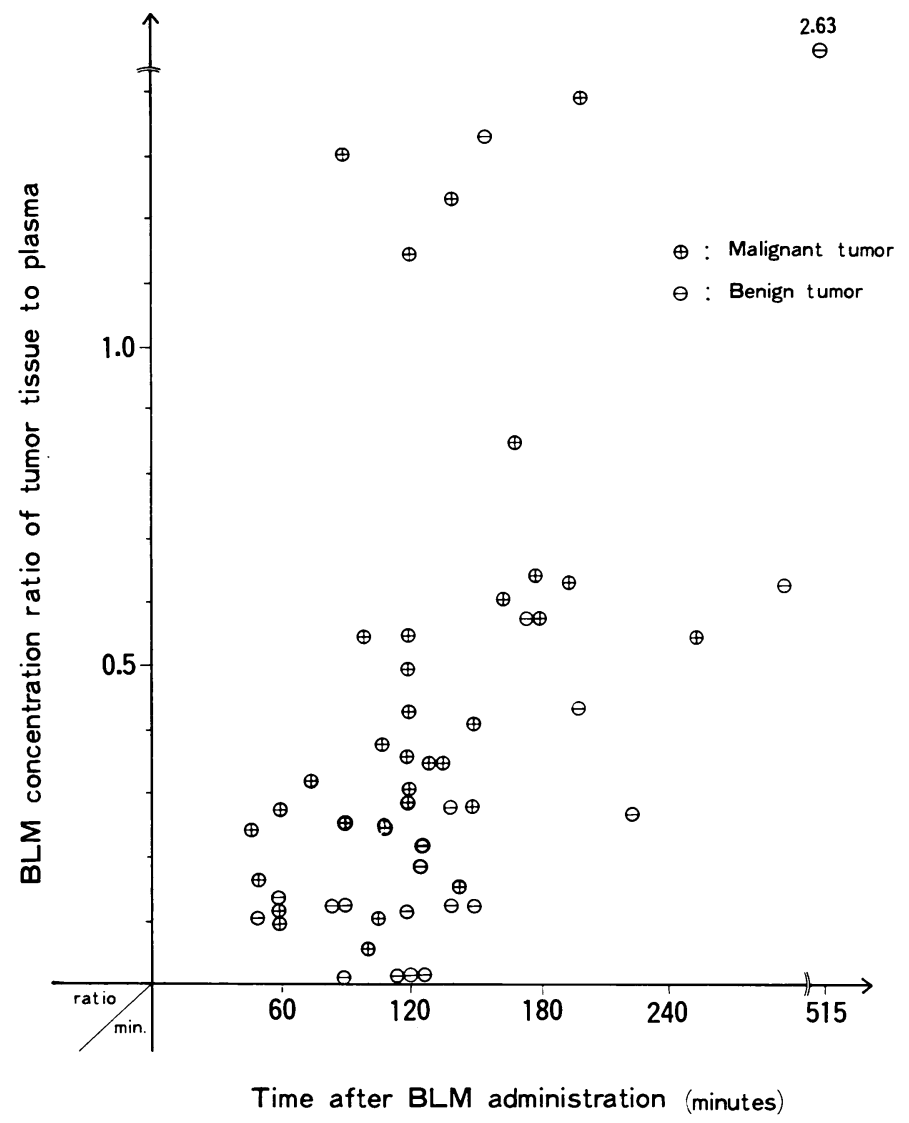

FIG. 3 Correlation between tumour tissue to plasma concentration ratio of bleomycin (BLM) after intravenous administration and histological malignancy of tumours.

Time after BLM administration (minutes)

moval in 14 cases. No BLM was detected from any of these brain tissue samples.

Cerebrospinal fluid (CSF) samples were also collected during surgery after BLM administration in eight cases. BLM was not detected from these samples either, except for one in which $0.07 \mu \mathrm{g} / \mathrm{ml}$ of $\mathrm{BLM}$ was measured at $120 \mathrm{~min}$ after BLM administration.

INTRAVENTRICULAR ADMINISTRATION OF BLM Two tumour tissue specimens of medulloblastomas in the fourth ventricle and one specimen of cyst content from a haemangioblastoma in the vicinity of the fourth ventricle were collected for BLM measurement after intraventricular administration. The collection times of these three samples were at 100,120 , and 270 minutes after BLM administration, and the concentrations and $\mathrm{T} / \mathrm{P}$ or $\mathrm{C} / \mathrm{P}$ ratios of these samples were $0.16 \mu \mathrm{g} / \mathrm{g}(\mathrm{T} / \mathrm{P}, 0.16 / 0), 0.72 \mu \mathrm{g} / \mathrm{g}(\mathrm{T} / \mathrm{P}$, $3.60)$, and $0.32 \mu \mathrm{g} / \mathrm{ml}(\mathrm{C} / \mathrm{P}, 0.32 / 0)$, respectively.

\section{DISCUSSION}

The first selection of a drug for chemotherapy of tumour should depend not only on the effectiveness of the drug against the tumour but also on the possibility of sufficient incorporation of the drug in active form into tumour tissue. It would be especially important and interesting to study the distribution of the drug in brain tumour in relation to the existence of a blood brain barrier which would limit the drug entrance into the brain tissue from circulating blood. A considerable amount of research on the uptake and distribution of chemotherapeutic agents in brain tumour has been carried out experimentally, but little work has been as yet done clinically. 


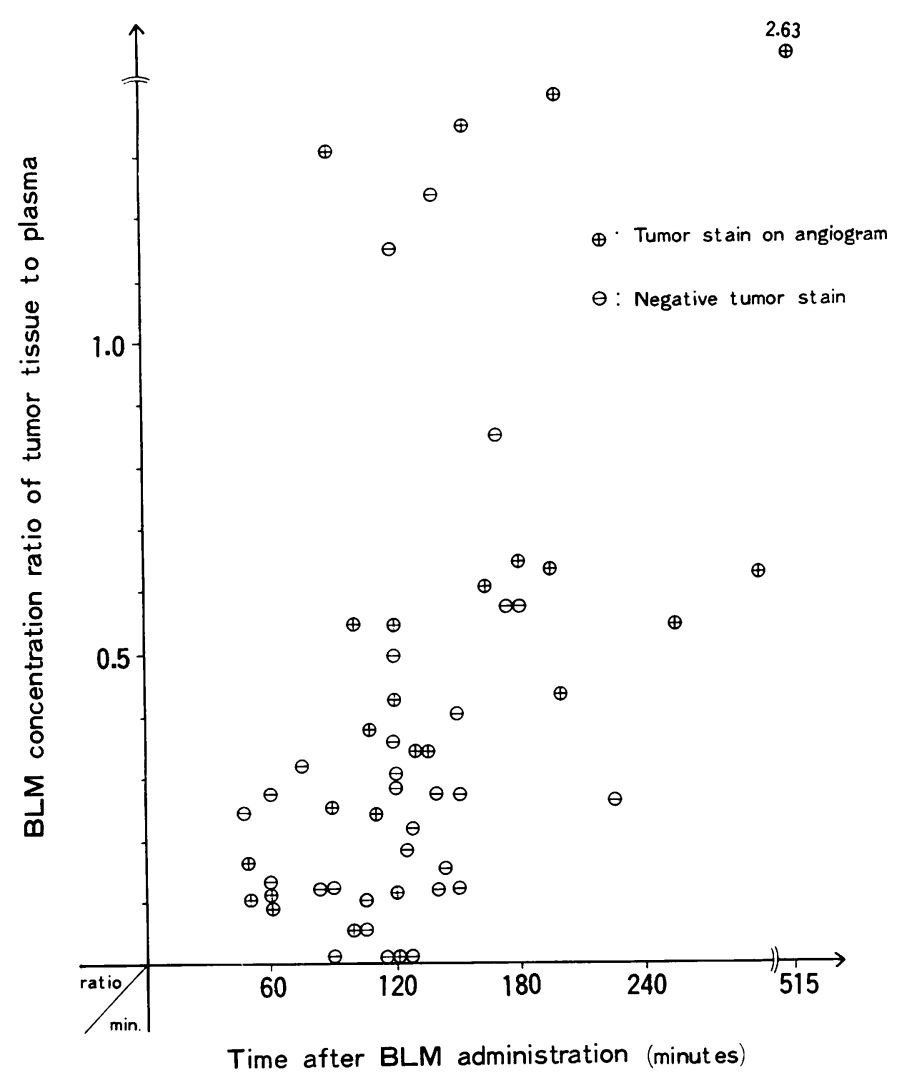

FIG. 4 Correlation between tumour tissue to plasma concentration ratio of bleomycin (BLM) after intravenous administration and existence of tumour stain on angiograms.

In a review, Soloway (1972) stressed that the first and crucial factor among the several factors which must be considered for affecting the permeability of brain tumours to pharmacological agents is the drug metabolism-that is, 'does the compound which is incorporated in the neoplasm have the same structure as the compound administered?'.

Investigating the distribution of BLM in organs, Umezawa et al. $(1967,1968 \mathrm{a}, \mathrm{b})$, who discovered BLM, employed two methods (1) bioassay using $B$. subtilis and (2) radioactive assay using ${ }^{3} \mathrm{H}$ - or ${ }^{14} \mathrm{C}$-bleomycin, for the determination of the distribution of BLM compounds in tissue. They considered that the compounds detected by bioassay would preserve antitumour activity and called the compounds 'active form'; meanwhile the determination by radioactive assay would show the distribution of total compounds of BLM (active form + inactive form). Based on this view, they suggested that the marked therapeutic effect on squamous cell carcinoma of BLM and the toxic side-effects which appear characteristically in the skin and lung were related to the high distribution of BLM in active form in these organs (Umezawa et al., 1967, 1968a, b).

It has been suggested that BLM might be effective against brain tumour, since the central nervous system, like the skin, is an ectodermal organ, and some clinical experiences as to the treatment of brain tumours with BLM have been reported (Takeuchi, 1969; Takeuchi et al., 1972).

Subsequently, the uptake and distribution of BLM in mice with methylcholanthrene induced glioma was investigated by us (Hayakawa et al., 1974) by radioactive assay and bioassay with ${ }^{14} \mathrm{C}$-bleomycin $\mathrm{A}_{2}$ (the main compound of BLM). The results showed that a relatively large amount of BLM may be taken up selectively in glioma after intravenous administration, and about two-thirds of the compounds distributed 


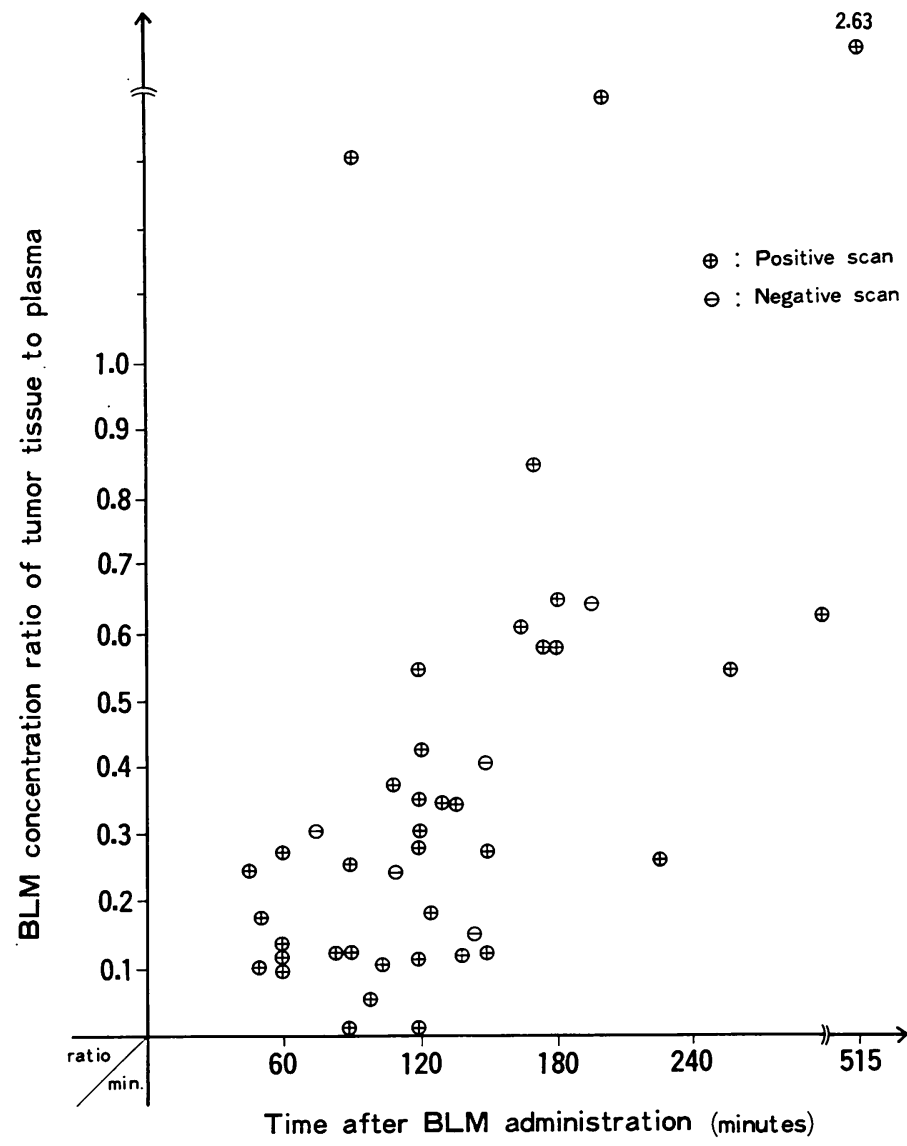

FIG. 5 Correlation between tumour tissue to plasma concentration ratio of bleomycin (BLM) after intravenous administration and findings of brain scan with Tc-99m.

in glioma may remain in the so-called 'active form'. These findings were essentially in accord with those reported by others (Kanno et al., 1970; Nishida et al., 1974) with other kinds of experimental brain tumour models. The present findings confirm these experimental results and clearly demonstrate that BLM administered intravenously may distribute selectively in tumour tissue of the brain in the so-called 'active form'.

Evidence obtained also indicates that the distribution of BLM in brain tumour may be related to the tumour malignancy, though there may not be significant correlation between the BLM distribution in brain tumour and the findings of cerebral angiograms as to the tumour stain, and the findings of brain scintillography with Tc-99m.

As to the mechanism which underlies the high correlation between the BLM uptake by intracerebral tumour tissue and the tumour malignancy, there are at least two possible explanations. The first is that BLM uptake by tumour tissue in the brain may depend upon tumour cell metabolism, possibly upon mitotic activity of tumour cells, whether or not the blood brain barrier exists in tumour tissue. This view would be reasonably understandable if the drug action of BLM as a cytostatic agent is considered, and would be supported by the observation that, with regard to meningioma, which is both an intracranial and an extracerebral tumour, higher concentration of BLM was found in the tumours showing histological malignancy. The second possible explanation is that the blood brain barrier in brain tumour tissue of higher malignancy might be more defective (Hossmann, 1967) and less limiting to drug entrance into the 
tumour tissue. Probably, both mechanisms may explain the results.

Graul et al. (1967), who have made drug distribution studies using tritiated cyclophosphamide, suggested that the drug concentration in the tumour is largely dependent upon the blood supply to the tissue. If it is accepted that the tumour stain on cerebral angiography indicates abundant blood supply to the tumour, the findings obtained by us do not support the view that uptake of BLM by the tumour is dependent on blood supply.

The mechanism of Tc-99m pertechnetate uptake by brain tumour is not yet entirely understood. At any rate, our results indicate that the mechanism which underlies the incorporation of BLM into brain tumour tissue might be different from that of Tc- $99 \mathrm{~m}$ pertechnetate. This view supports the recent observation by Mamo et al. (1973). They developed a new isotope method for the detection of cerebral tumour using ${ }^{57} \mathrm{Co}-$ BLM and demonstrated the superiority of this method to that using Tc-99m for the diagnosis of malignant intracranial tumours, especially of metastatic lesions in the brain. The mean count ratios of tumour to healthy brain on brain scan obtained from metastasis, glioblastoma, astrocytoma, and meningioma reported by them were $3.8,2.8,1.7$, and 1.4 respectively. Our observations from the same types of tumour were 0.73 , $0.51,0.34$, and $0.32 \mu \mathrm{g} / \mathrm{g}$ in that order. There is a remarkable agreement between these two results, and our observations appear to support the demonstration by Mamo et al. (1973).

Takeuchi (1969) made the first systematic clinical application of BLM to the treatment of brain tumours. Takeuchi et al. (1972) also investigated the distribution of BLM in brain tumours but failed to detect BLM in glioma tissue by bioassay in most of the cases examined. The diversity between their findings and ours may be due to the difference of the dosage of BLM administered and the collection times of tumour samples.

As to craniopharyngioma, a chemotherapeutic effect of BLM has been expected because of the histological similarity of the tumour to the squamous cell carcinoma of the skin. However, the BLM distribution in the cyst contents or tumour tissues of craniopharyngioma was less than expected.
High distributions of chemotherapeutic agents in the pituitary tissue and the 8th cranial nerve after intravenous or intracarotid administration in normal animals were demonstrated by Mahaley et al. $(1961,1962)$ and by us (Hayakawa et al., 1968). It would be of interest to know that the BLM concentrations of cyst contents were remarkably high in both of two Schwannoma cysts of the 8th cranial nerve and one out of two pituitary adenoma cysts, though the concentrations in the tumour tissues of Schwannoma and pituitary adenoma were not so high, except in a case of pleomorphic type of pituitary adenoma.

It is clear from the present data that little BLM distributes in the brain tissue or in CSF as 'active form'. Evidence to date would clearly indicate that the blood brain barrier and the blood-CSF barrier may limit BLM entrance into brain tissue and CSF from blood, though it is still possible that, even if BLM should be incorporated in the brain tissue or CSF, it would be rapidly metabolized and inactivated.

We (Ushio et al., 1974) have demonstrated the selective uptake and distribution of ${ }^{3} \mathrm{H}$-metho: trexate in glioma induced by 20 -methylcholan threne after intrathecal administration in mice Our findings in the present study indicate that considerable amount of BLM may be taken up by tumour tissue located close to the CSF path= way after intraventricular administration. The low plasma concentration of BLM after intraventricular administration would suggest that there may be less systemic toxic side effects. The available evidence indicates that intrathecal chemotherapy may be useful and effective in some cases of brain tumours.

Our present observations were based on the measurement of BLM by bioassay. Consequently, the detected compounds of BLM were only those which preserved antibacterial activity in the tissues to which it was distributed, as the so-called 'active form'. The distributions of the metabolized or 'inactivated' compounds were still unknown. However, if the antitumour activity is related to antibacterial activity, the information obtained might be useful for chemotherapy of brain tumours with BLM.

Grateful acknowledgement is made to Dr H. Umezawa for his constant interest and valuable suggestions in this investigation. Thanks are tendered to Dr T. Ikeda and 
Dr L. Tai for brain scan diagnosis, and to the staffs of the Department of Neurosurgery, Osaka University Hospital and Osaka Kosei-Nenkin Hospital.

\section{REFERENCES}

Graul, E. H., Schaumloeffel, E., Hundeshagen H., Wilmanns, H., and Simon, G. (1967). Metabolism of radioactive cyclophosphamide. Animal tests and clinical studies. Cancer, 20, 896-899.

Hayakawa, T., Ushio, Y., Mogami, H., and Horibata, K. (1974). The uptake, distribution and anti-tumor activity of bleomycin in gliomas in the mouse. European Journal of Cancer, 10, 137-142.

Hayakawa, T., Yamada, R., Kanai, N., Kuroda, R., Higashi, H., Mogami, H., and Jinnai, D. (1968). Experimental studies on chemotherapy of brain tumor. 2. Localization of cytostatic agents in nervous tissue after intravenous, intracarotid and intrathecal administration. Medical Journal of Osaka University, 18, 389-395.

Hossmann, K. A. (1967). Morphological substrate of the blood-brain barrier in human brain tumors. In Brain Edema, pp. 249-258. Edited by I. Klatzo and F. Seitelberger. Springer: New York.

Ichikawa, T. (1967). Treatment of squamous cell carcinoma with a new antitumor antibotic, Bleomycin (BLM). Japanese Medical Journal, 2269, 37-40. (In Japanese.)

Ichikawa, T., Matsuda, A., Miyamoto, K., Tsubosaki, M., Kaihara, T., Sakamoto, K., and Umezawa, H. (1967). Biological studies on bleomycin A. Journal of Antibiotics, 20A, 149-155.

Ichikawa, T., Nakano, I., Hirokawa, I., and Murata, M. (1968). On the treatment of skin tumors, including penile cancer, with bleomycin. Chemotherapy, 16, 882-903. (In Japanese.)

Kanno, T., Kudo, T., Nakazawa, T., Takeuchi, T., and Umezawa, H. (1970). Bleomycin as an anti-brain tumor antibiotic. Part 2. The distribution of ${ }^{3} \mathrm{H}$-bleomycin $\mathrm{A}_{2}$ $(-\mathrm{Cu})$ in the experimental brain tumor of mouse. Clinical Neurology, 10, 501-506. (In Japanese.)

Mahaley, M. S., Jr, Huneycott, H., Boone, S., and Woodhall, B. (1961). Localization of methyl-bis-(2-chloroethyl$1,2-\mathrm{C}^{14}$ ) amine hydrochloride in nervous tissue after intravenous injection or regional cerebral perfusion in dogs. Cancer Chemotherapy Reports, 11, 29-32.

Mahaley, M. S., Jr, and Woodhall, B. (1962). The effect of anticancer agents on nervous tissue. Cancer Chemotherapy Reports, 16, 543-544.

Mamo, L., Nouel, J. P., Robert, J., Chai, N., and Houdart, R. (1973). Use of radioactive bleomycin to detect malignant intracranial tumors. Comparative study with technetium$99 \mathrm{~m}$ in 104 cases. Journal of Neurosurgery, 39, 735-741.

Nishida, K., Tsuchida, T., Miyazawa, N., Honda, T., Ueki, K., and Kumanishi, T. (1974). Uptake of bleomycin in mouse brain tumors induced by Rous sarcoma virus. Committee of clinical research of bleomycin. Proceedings of the 5th Brain Tumor Meeting, 5, 48-52. (In Japanese.)

Soloway, A. H. (1972). Factors affecting the permeability of brain tumors to pharmacologic agents. In The Experimental Biology of Brain Tumors, pp. 407-428. Edited by W. M. Kirsch, E. G. Paoletti, and P. Paoletti. Thomas: Springfield, Ill.

Takeuchi, K. (1969). Clinical effect of bleomycin on brain tumor. Japanese Medical Journal, 2375, 17-18. (In Japanese.)

Takeuchi, K., Atsuji, M., Masui, T., Sueyoshi, S., Hara, M., Okada, M., Ogiwara, R., and Oyama, M. (1972). Chemotherapy of brain tumor. Effect of bleomycin. Brain Nerve, 24, 437-444. (In Japanese.)

Umezawa, H., Ishizuka, M., Hori, S., Chimura, H., Takeuchi, T., and Komai, T. (1968b). The distribution of ${ }^{3} \mathrm{H}$-bleomycin in mouse tissue. Journal of Antibiotics, 21A, 638-642.

Umezawa, H., Ishizuka, M., Kimura, K., Iwanaga, J., and Takeuchi, T. (1968a). Biological studies on individual bleomycins. Journal of Antibiotics, 21A, 592-602.

Umezawa, H., Ishizuka, M., Maeda, K., and Takeuchi, T. (1967). Studies on tleomycin. Cancer, 20, 891-895.

Umezawa, H., Maeda, K., Takeuchi, T., and Okami, Y. (1966a). New antibiotics, bleomycin A and B. Journal of Antibiotics, 19A, 200-209.

Umezawa, H., Suhara, Y., Takita, T., and Maeda, K. (1966b). Purification of bleomycins. Journal of Antibiotics, 19A, 210-215.

Ushio, Y., Hayakawa, T., and Mogami, H. (1974). Uptake of tritiated methotrexate by mouse brain tumors after intravenous or intrathecal administration. Journal of Neurosurgery, 40, 706-716. 